http://www.inass.org/

\title{
Research and Implementation of the Temperature Control System for the Sintering Shaft Furnace
}

\author{
Guohuan Lou* Jianmin Wang Jiawei Wang Fuxing Yu \\ Hebei Polytechnic University, Tangshan Hebei ,China \\ *Corresponding author's Email: zdhua@heut.edu.cn
}

\begin{abstract}
This paper describes the implementation of the temperature control system for sintering shaft furnace. In order to solve the problems caused by pure time-delay and non-linearity, an intelligent serial temperature control system is introduced in this paper, where the fuzzy controller is used in the main control loop and the fuzzy neural network PID controller is adopted in auxiliary loop. Simulation results show that this system is stable and has stronger anti-interference capability. Finally, the hardware and software implementation methods for the firebox temperature control system are introduced. The real production results demonstrate that production requirements are met and better control effects are obtained. The aim of energy saving and consumption reduction and quality improvement is achieved.
\end{abstract}

Keywords: Sintering shaft furnace; Temperature; Serial control; Fuzzy PID

\section{Introduction}

The sintering pellets are important raw materials for blast furnace iron smelting [1]. The Shaft furnace is the device used to roast the sintering pellets. It has some advantages such as simple structure, no requirements to special materials, lower costs, higher thermal efficiency and being convenient to maintain and operate. However, its lower production and poorer adaptability to raw materials can not satisfy the requirements of modern blast furnace for raw materials, so shaft furnace has hardly been used overseas. But considering the current domestic circumstances, the sintering shaft furnace is still the main device for pellet production in some middling or small-sized pelletizing plants in China [2].

The sintering process is a complex physical chemistry process, in addition, the sintering technique has a direct influence on the pellet quality and output and energy consumption. Therefore, about what the sintering producers concern the most is how to ensure stable production with higher quality and lower energy consumption.
PLC is a common application technology in sintering shaft furnace automatic control and PID control method is the general control strategy. For example, the control systems of $1 \#$ and $2 \# 8 \mathrm{~m}^{2}$ shaft furnaces completed in 1999 and 2000 at Magang pelletizing plant use Huaguang SU-6B PLC [3]. In ShanXi New Lingang, PLC is also used for the $8 \mathrm{~m}^{2}$ shaft furnace and PID control method is adopted in temperature control. In pelletizing plant of Jinan Iron and Steel Company Ltd, SUPCON-JX300 distributed control system is used and PID control is adopted for air flowrate in firebox temperature self-optimization control. The PID control theory is that as the firebox temperature changes consistently, the ratio of gas to air must be revised accordingly, in order to obtain stable temperature [4].

In recent years, the simple PID control has been replaced gradually by advanced control technique and methods in some newly-built or reconstructive shaft furnaces. Take the $8 \mathrm{~m}^{2}$ and $10 \mathrm{~m}^{2}$ shaft furnaces newly-built in Daye iron ore mine pelletizing plant for example, their control schemes are double-level-controlled with the upper computer uses industrial personal computer and lower computer uses PLC and ST2000. The control 
method combining neural network with PID is used for shaft firebox temperature control. Two PID closed regulate loops are used to form gas and air ratio regulating system for firebox temperature control [5].

Although the methods discussed in paper [4] and [5] can stabilize the firebox temperature within the range required for production, the control result may still change the total gas consumption, which may bring unfavorable effects to pellet roasting. In order to keep stable firebox temperature as well as unchanged gas consumption, based on advanced control technology, a serial temperature control system for sintering pellet furnace is designed in this paper. Simulation experiments and practical operation results show that this control system has a better control effect on improving control precision and reducing energy consumption.

\section{The basic structure of the shaft furnace and burning condition analysis}

The structure of the shaft furnace is shown in Figure 1.

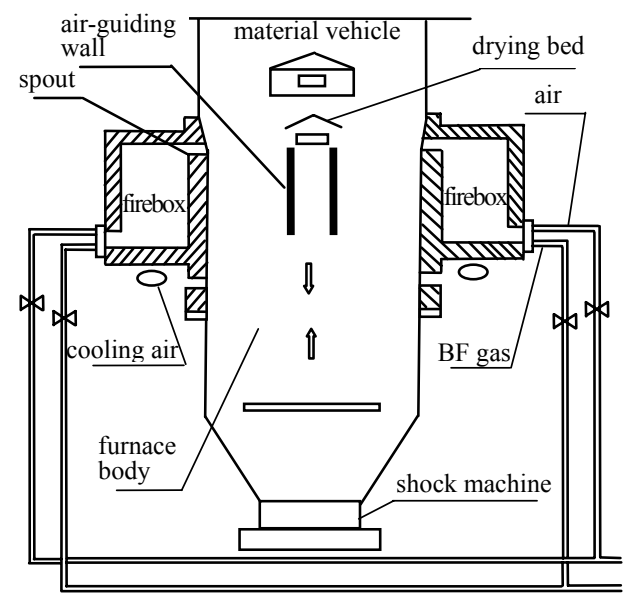

Figure. 1 The structure of shaft furnace

Where, the air-guiding wall and the drying-bed are the special structures of the $8 \mathrm{~m}^{2}$ shaft furnaces in China. The producing process includes scattering the raw pellets on the drying-bed by the small material vehicle first of all, then drying them through the preheating zone, roasting zone, equal-heating zone and cooling zone in turn; finally, discharging the pellets broken by roller via the electric shock machine and carrying the pellet away through the conveyor belt.

The heating process is that the gas and combustion-supporting air are mixed and burnt in the firebox, the hot mixed-gases are spouted into the shaft furnace through the spout. Then crude pellets are roasted by the mixed gas. In the end, the exhausted gas and cooling air are given off from the flue. The air-guiding wall is used to improve the distribution of the air field and the temperature field and so that the output and quality of the pellets can be enhanced

The shaft furnace uses the blast furnace (BF) gas as fuel. Therefore the BF gas producing status affects the shaft furnace burning status in many ways. In the producing process, the flowrate and thermal value of the BF gas vary because of the periodicity of the iron making process. When the blast furnace is in normal status, the effective ingredients for burning and the thermal value will reduce. Otherwise, the effective ingredients for burning and the thermal value will increase. Even if the supply of blast furnace gas is in normal, the flowrate and pressure of the gas will still change. For example, the gas pressure will fall down because the consumption of gas is greater in winter.

The burning status and the quality of pellets will also be affected by the quantity of the air. When the flowrate of fuel is steady, the firebox temperature will vary with the change of the air valve's position. When the air valve is near to a certain position, the temperature of the firebox will go up to the maximum. Theoretically, when the temperature of the firebox is in maximum, the mixture of air and the fuel is almost at optimal proportion. In this case, if cool air is over spouted, the surplus cool air will reduce the firebox temperature. If the cool air quantity is under spouted, the firebox temperature will also fall down, as the fuel can't be burnt completely. Since the process of producing pellets is an oxidation process, the oxidation condition must be satisfied. Otherwise, the compounds of low melting point will be produced and even agglomeration will be occurred in the shaft furnace. So a correct quantity of air distribution is very important.

\section{The serial control strategy of firebox temperature}

\subsection{The structure of serial temperature control system}

Based on the above reasons, generally, the flowrate of gas and combustion-supporting air are taken as the control object for temperature control of 
the firebox of sintering shaft furnace. PID control method is used mostly [4]. Fuzzy PID and neural network PID control methods are also adopted [5].

The control theory of paper [4] is that according to the amount of crude pellets, firstly, the amount of gas required is calculated; and then according to the temperature change rate of the firebox, the optimum air/gas ratio is figured out; finally, based on the air/gas ratio and flowrate of gas, the value of air given is determined. PID control strategy is used to decide the gas flowrate and combustion-supporting air flowrate.

The method used in paper [5] is that the gas flowrate is adjusted to the firebox temperature, which in turn, together with a fixed air/gas ratio, decides the amount of to the combustion-supporting air.

The corresponding control ways are shown in Figure 2.
From Figure 3, we know that this system is composed of two serial control subsystems with one main controller [6]. The main controller in the main loop is composed of fuzzy controller[7], whose output is the change rate of air/gas ratio $X$. Using the output of main controller, the change rate of air/gas ratio $X$, and the total amount of exhaust gas $S$, we can calculate out the given input of the two auxiliary loops. The neural network fuzzy controller is used in two auxiliary loops, gas flowrate control loop and air flowrate control loop. The control method of system is described as follows:

Firstly, according to the requirement of pellet output, the total gas consumption $S$ that is needed can be calculated.

Calculating formula is: $S=Q \times M$

Where, $S$ - the total gas consumption

$Q$ - pellet output

$M$ - the ratio of the total gas consumption to
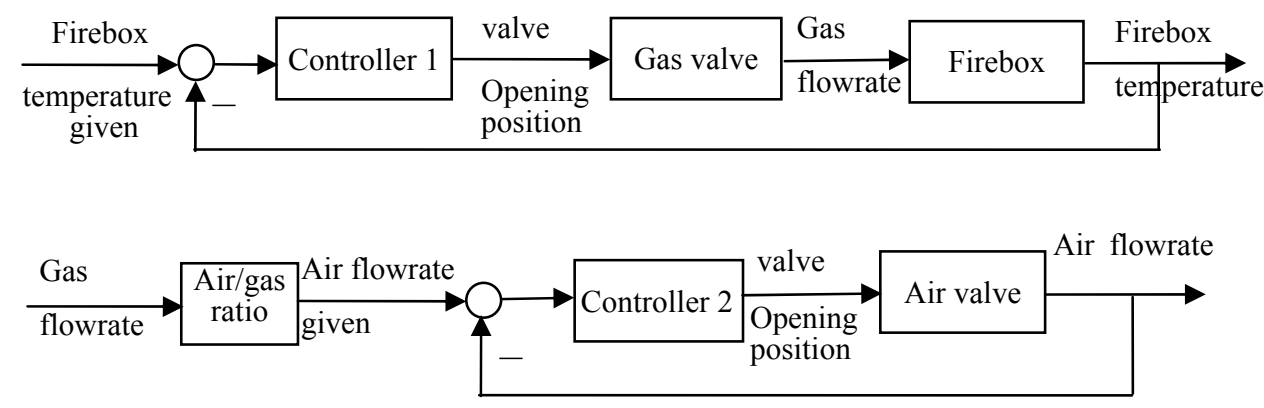

Figure. 2 Block diagram of firebox temperature control system with fixed air/gas ratio

Although the previous two methods can both stabilize the firebox temperature within the technique range required, the control results will lead to the change of total gas consumption. For example, in paper [5], when the air/gas ratio is fixed, if the gas flowrate increases or decreases, the combustion-supporting air will also increase or decrease consequently. So, the total gas consumption will change and bring about bad effects on pellet calcinations. In order to ensure stable firebox temperature and maintain the total gas consumption within certain range, the previous two methods are improved. The gas flowrate and combustion-supporting air flowrate, that is the total gas consumption, is kept unchanged. Under this condition, the gas flowrate and combustion supporting air flowrate are controlled by adjusting air/gas ratio respectively. So the firebox temperature can be kept stable. The block diagram of firebox temperature control system is shown in Figure 3. pellet output.

Then, using fuzzy controller in the main loop, the change value $X$ of air/gas ratio can be obtained, in terms of error $e$ between the given temperature and actual firebox temperature and error change ec . According to the formula:

$$
K=K_{c}+X \cdot m
$$

Where: $K-$ new air/gas ratio

$$
\begin{aligned}
& \mathrm{Kc} \text { - current air/gas ratio } \\
& X \text { — change value of air/gas ratio } \\
& m \text { - base value of air/gas ratio ( here is } 0.02 \text { ) }
\end{aligned}
$$

According to formula (2), the new air/gas ratio $K$ can be calculated.

Therefore, the given value of gas is 


$$
r_{g}=\frac{S}{1+K}
$$

The given value of air is

$$
r_{a}=\frac{S K}{1+K}
$$

Using the new given value calculated from formulas (3) and (4), we can control the gas flowrate and air flowrate in the two auxiliary loops to keep the temperature within the range required. ec and output $X$ are $\{\mathrm{NB}, \mathrm{NM}, \mathrm{NS}, \mathrm{ZE}, \mathrm{PS}, \mathrm{PM}$, PB $\}$.

Then, according to the expert experiences and actual production process, control rule tables are generated. In order to satisfy the requirements of real time control and to reduce the operations on line, firstly, all outputs corresponding to the different inputs are calculated off line to form a control table. We only need to look at this table on real time control.

After calculating out the change of air/gas ratio $\mathrm{X}$, using formula $K=K_{c}+X \cdot m$, we can calculate

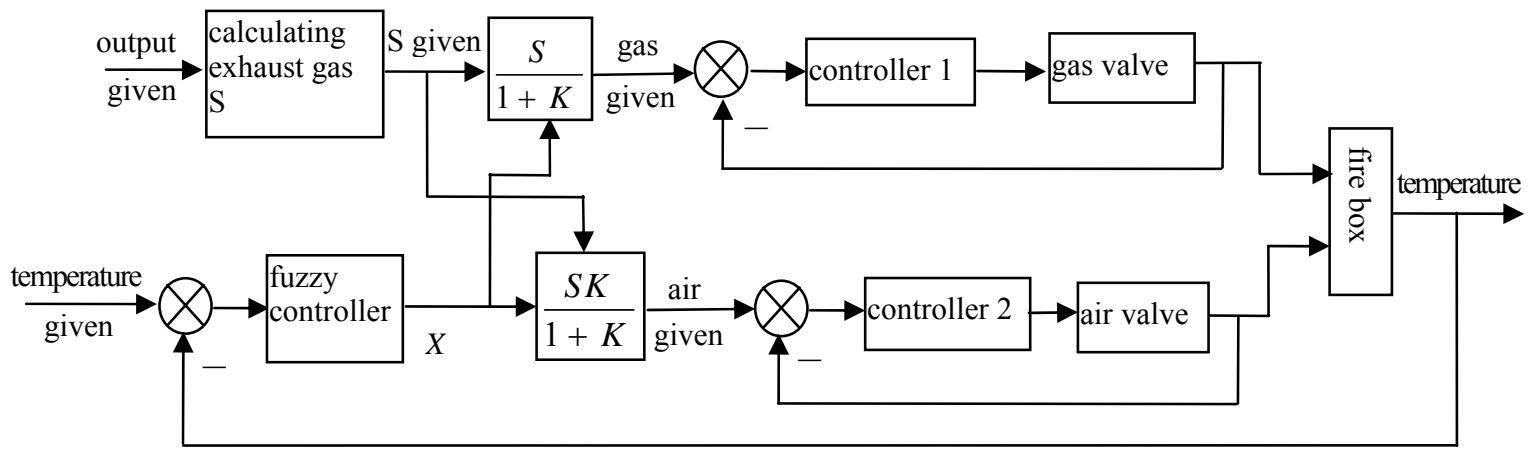

Figure. 3 The block diagram of firebox temperature control

The firebox temperature control system of sintering shaft furnace is a non-linear, time-delay system with distributed parameters. In addition, the change of gas calorific value also has influence on the firebox temperature. Therefore, and it is hard to describe with mathematics models accurately.

However, fuzzy control technology is an intelligent control that is developed by means of human experiences and logic deduction. It has been used in many fields successfully. So, we use fuzzy control to adjust the air/gas ratio.

\subsection{The design of air/gas ratio fuzzy controller}

Two-dimension fuzzy controller is adopted to control the air/gas ratio. There are two inputs in this system. One is the error e which stands for the difference between given temperature $r$ and output feedback y, the other is the error change ec.

Here, the range of $\mathrm{e}$ is $-50^{\circ} \mathrm{C} \sim+50^{\circ} \mathrm{C}$ and the fuzzy set is $\{-6,-5,-4,-3,-2,-1,0,1,2,3,4,5,6\}$.

The range of ec is $-10^{\circ} \mathrm{C} \sim+10^{\circ} \mathrm{C}$ and the fuzzy set is $\{-5,-4,-3,-2,-1,0,1,2,3,4,5\}$. Output is the change of air/gas ratio $\mathrm{X}$ and its change range is $-5 \sim+5$.

Fuzzy semantic values of error e, error change new air/gas ratio $K$ and get the input values of gas and air.

\section{- 3.3 The structure of fuzzy neural network PID controller}

In order to have higher control precision to the auxiliary loop, fuzzy neural network PID control is used. The control principle of gas flowrate control and air flowrate control is the same. The block diagram of gas control loop is shown in Figure 4.

Where, the controller is composed of three sections.

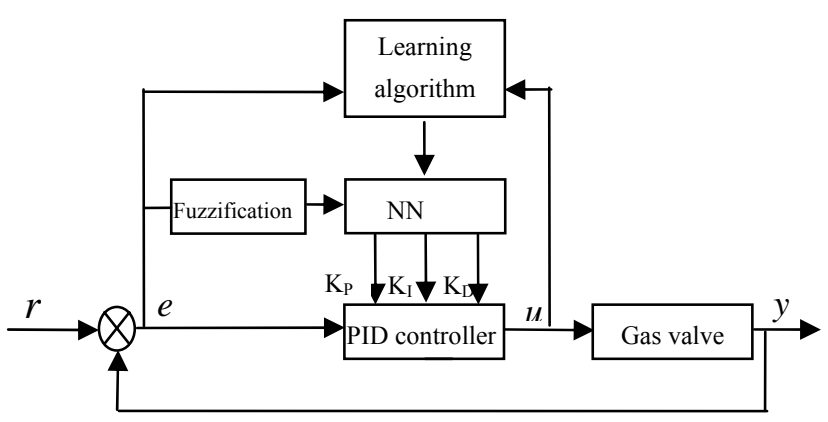

Figure. 4 The block diagram of gas control 
(1) Conventional PID controller, which directly controls the plant and three parameters, $K_{p}, K_{i}$ and $K_{d}$ are adjusted on line;

(2) Fuzzification module, which is used to fuzzificate and normalize the system status variables;

(3) Neural networks (NN), which is used to denote fuzzy rules. Via the learning with $\mathrm{NN}$ [8-9], they are presented in weight coefficients and the generation of rules is turned to the choosing and updating of weight coefficients. The outputs of NN correspond to the optimum PID parameters $K_{p}, K_{i}$ and $K_{d}$.

\section{- 3.4 The design of fuzzy neural network PID controller}

From previous analysis, we know that fuzzy $\mathrm{NN}$ controller is a fuzzy controller with two inputs and three outputs, in which inputs are the flowrate error $e$ and error change $e c$, outputs are the parameter $K_{p}, K_{i}$ and $K_{d}$ of PID controller. In practical application, based on the given flowrate, via adjusting the three parameters of PID on-line, the valve position is changed. Thereby the flowrate of gas is changed and required temperature is obtained. The structure of fuzzy neural network is shown in Figure 5.

First layer is input layer with two nodes which are both input nodes. They transmit the signals into the next layer directly. That is,

$$
\begin{aligned}
n e t_{i}^{(1)} & =x_{i}, i=1,2 \\
O_{i}^{(1)} & =x_{i}
\end{aligned}
$$

Where,

$n e t_{i}^{(j)}$-the input of ith nerve cell in jth layer;

$O_{i}^{(j)}$-the output of ith nerve cell in jth layer;

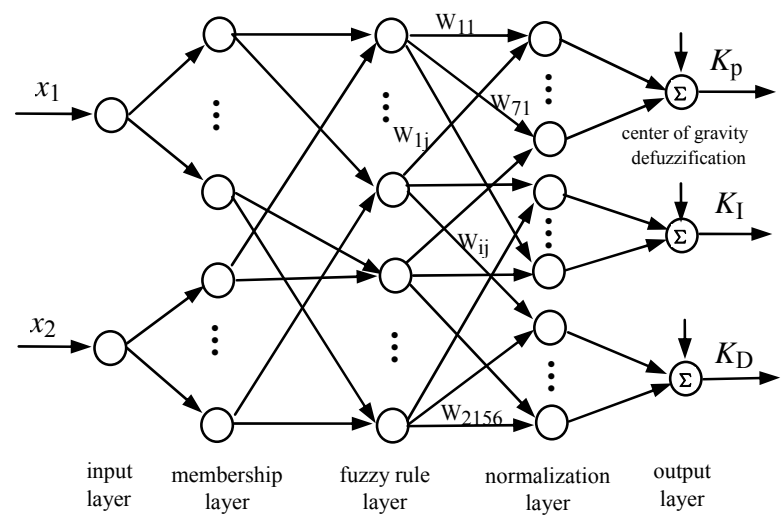

Figure. 5 Fuzzy neural network architecture $x_{1}$ - flowrate error; $x_{1}=e=y-r$;

$x_{2}$-flowrate error change;

$x_{2}=e c=[e(t+1)-e(t)] / T,(T$ is sampling cycle $)$.

The connection weight of the first layer is 1 .

Second layer represents the fuzzy semantic variable of input. Such as positive big (PB), positive middle (PM), positive zero (PZ), negative big (NB) and so on. The fuzzy set for first input variable includes 8 language variable values, that is, $\{P B$, PM, PS, PZ, NZ, NS, NM, NB . The fuzzy set for second input variable contains 7 language variable values, that is, $\{\mathrm{PB}, \mathrm{PM}, \mathrm{PS}, \mathrm{ZO}, \mathrm{NS}, \mathrm{NM}, \mathrm{NB}\}$. The fuzzy set elements of two inputs are 8 and 7 respectively. The nodes in this layer are used to implement the membership function of input variables. So, we can get

$$
\begin{aligned}
& \text { net }_{i}^{(2)}=O_{j}^{(1)}, i=1,2, \cdots 15 \\
& \left\{\begin{array}{l}
j=1(i \leq 8) \\
j=2(8<i \leq 15)
\end{array}\right. \\
& O_{i}^{(2)}=\exp \left[-\left(\frac{n e t_{i}^{(2)}-m_{i}^{(2)}}{\sigma_{i}^{(2)}}\right)\right]
\end{aligned}
$$

Where, $m_{i}$ and $\sigma_{i}$ are the center and width of membership function in Gauss for input $x_{i}$ and they are adjustable parameters. The connection weight of the second layer is 1 .

Third layer contains $8 \times 7$ nodes and each node denotes a fuzzy rule. The connection between second and third layer is used to match fuzzy rule conditions. The outputs of this layer represent incentive intensity of every rule:

$$
\begin{gathered}
n e t_{i}^{(3)}=\left(O_{j}^{(2)} \cdot O_{k}^{(2)}\right) \quad i=1,2, \cdots 56 ; \\
j=1,2, \cdots 8 ; \quad k=9,10, \cdots 15 \\
O_{i}^{(3)}=\text { net }_{i}^{(3)}, i=1,2, \cdots 56
\end{gathered}
$$

The fourth layer includes 21 nodes, where 7 nodes are fuzzy set for output variable $K_{p}, 7$ nodes for $K_{i}$ and 7 nodes for $K_{d}$. Each nodes in this layer perform fuzzy "OR" operation to synthesize rule consequent for output. The Mamdani fuzzy reasoning rules are used for output and the functions are as follows: 


$$
\begin{gathered}
n e t_{i}^{(4)}=\frac{\sum_{j=1}^{56} w_{i j} O_{j}^{3}}{\sum_{j=1}^{56} w_{i j}} \quad i=1,2, \cdots 21 \\
O_{i}^{(4)}=n e t_{i}^{(4)} \quad i=1,2, \cdots 21
\end{gathered}
$$

Where, $w_{i j}$ is the connection intensity between ith output value and $j$ th rule, whose value is changeable.

The fifth layer is used for defuzzification. The output variables of fourth layer is a member of fuzzy set, so that, improved center of gravity
Where, $k_{j}$ is the weight of fifth layer, here all are 0.25 .

Here the computation is intensive, however, the sample cycle is 10 seconds, so the controller can satisfy the actual production requirements.

\section{System simulation experiment}

According to the above scheme, a serial fuzzy control system is designed and the step response of the closed loop system is analyzed under the MATLAB simulation environment. The block diagram of system simulation is shown in Figure 6.

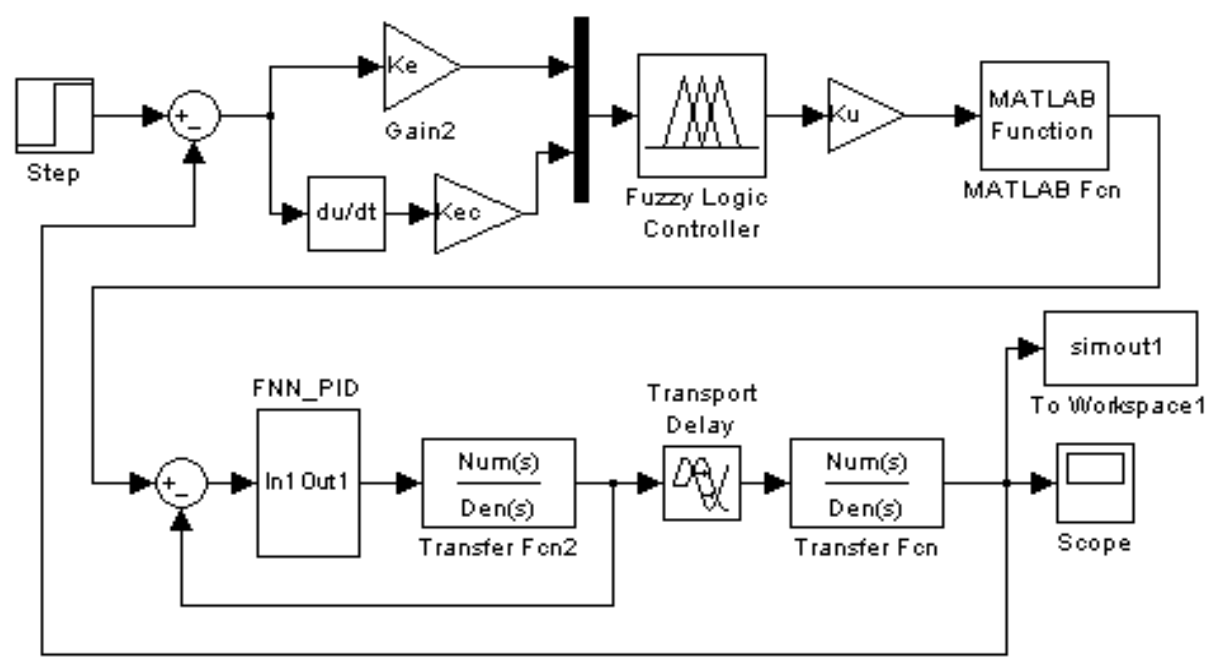

Figure.6 The block diagram of simulation

defuzzification method is used here:

$$
\begin{gathered}
K_{p}=\frac{\sum_{j=1}^{7} k_{j} O_{j}^{(4)}}{\sum_{j=1}^{7} k_{j}} \\
K_{i}=\frac{\sum_{j=8}^{14} k_{j} O_{j}^{(4)}}{\sum_{j=8}^{14} k_{j}} \\
K_{d}=\frac{\sum_{j=15}^{21} k_{j} O_{j}^{(4)}}{\sum_{j=15}^{21} k_{j}}
\end{gathered}
$$

Simulation experiment is made in two steps. Firstly, we simulate the auxiliary loops, air flowrate loop and gas flowrate loop, with the PID control and the fuzzy NN PID method. Secondly, after adjusting the auxiliary loops well, we simulate the main loop again.

In the fuzzy control of main loop, the proportion factor $K e=0.2, K e c=1, K u=50 . K u$ is the system open loop multiplication. The bigger the $K u$ is, the faster the debugging speed of system is. But, the stability is decreased. The simulation results in the comparison with the conventional PID, fuzzy PID controller and fuzzy NN PID method are presented in Figure 7. For the conventional PID control, the adjustment time $t_{\mathrm{s}}$ is $500 \mathrm{~s}$, overshoot $\delta \%$ is $15.2 \%$. For the fuzzy PID control, the adjustment time $t_{\mathrm{s}}$ is $810 \mathrm{~s}$, overshoot $\delta \%$ is $10.4 \%$. But, for the fuzzy NN PID control, the adjustment time $t_{\mathrm{s}}$ is $320 \mathrm{~s}$ and no overshoot.

The simulation results show that the fuzzy NN PID control method is reasonable and practical and 
the serial control system is superior to other methods.

Finally, the simulation for anti-interference is made. Figure 8 is the simulation curve where $80^{\circ} \mathrm{C}$ interference signal is added at 25 th sampling period $(1000 \mathrm{~s})$ and the output temperature reaches the requirement within 60s. From the curve it can be seen that the control system has stronger anti-interference capability.

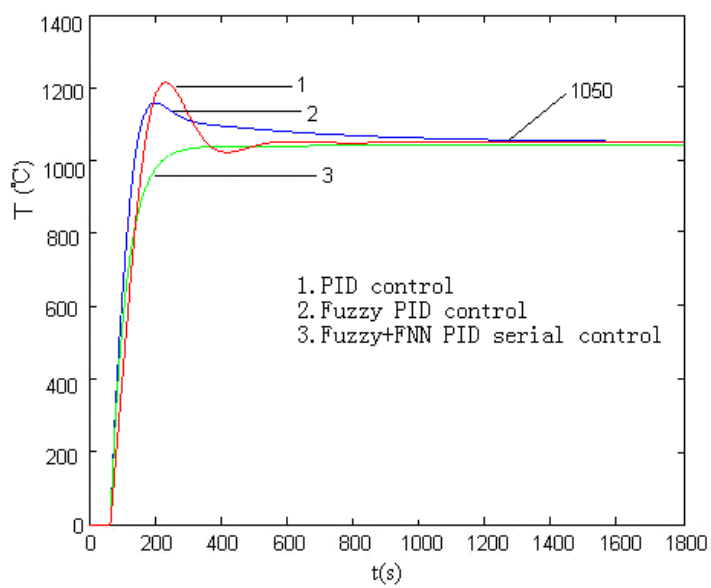

Figure. 7 Comparison of three methods step response

\section{The implementation of the firebox temperature control system}

\subsection{The constitute of system hardware}

This temperature control system is applied in the sintering factory of Xingtai Iron and Steel Company, China. It is implemented by distributed control system[10] and composed of PLC (Logix5000 family), special communication network, monitor computer and various instruments. The hardware constitute of temperature control system for sintering shaft furnace is shown in Figure 9.

Various physical data (such as gas and combustion-supporting air flowrate, temperature) are sent to PLC through instruments in $4 \sim 20 \mathrm{~mA}$ signals. PLC implements data collection, scale conversion, PID operation and valve controlling. The signals from job site are sent to host computer through PLC. The fuzzy control of the air/gas ratio, along with the fuzzy neural network PID control of gas and air flowrate are completed by the host computer so that different production requirements can be met. The

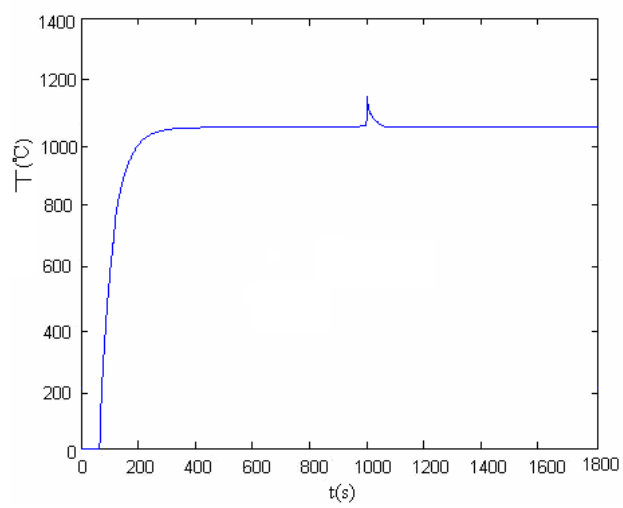

Figure.8 Response curve of system with interference

control signals sent from host computer drive the slave computers through the PLC and manual operator. Tackling the control signals, the slave computers transmit feedback signals from the valve status back. PLC plays a part of interface and it communicates with the host computer.

\subsection{Software design of the system}

Human-machine interface (HMI) of the system is designed with configuration software RSView which mainly completes intelligent control algorithm, logic and control, operation interface design. The temperature control software of firebox is realized with VBA.

According to actual production site requirements, the temperature control system for sintering shaft furnace mainly completes the following functions:

(1) On-line measuring and displaying for various thermal parameters;

(2) Control of air and gas ratio and firebox temperature of shaft furnace;

(3) To alarm when important events and parameters overflow;

(4) Display of Real-time data as well as storage management of historical data;

(5)Generating and printing of formatted report forms;

(6)System operation security and authority management;

(7) Remote monitor and maintenance of system.

To make the maintenance and extension of the system convenient, the system software is developed according to its hierarchy of function. The hierarchical architecture for system software is shown in Figure 10. 


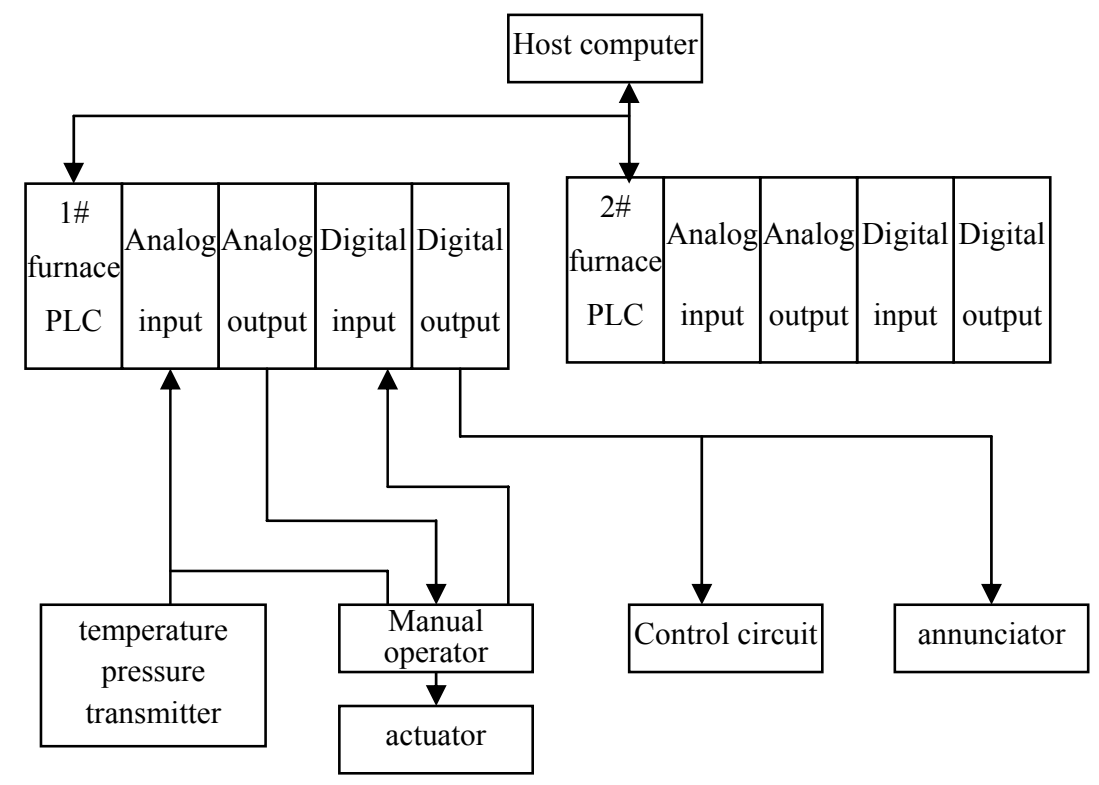

Figure. 9 Control system architecture

Based on system function requirements and the characteristics of the object controlled, Windows is used as operating system for the host computer and RSView32 industrial control configuration software is taken as development platform.

RSView32 is an industrial control configuration software that is used as supervisory control and data acquisition for the host computer data (SCADA) and human machine interface (HMI) with more powerful function and stronger development capacity. RSView configuration software supports DDE (Dynamic Data Exchange), OPC (open connectivity) and the VBA development environment. In addition to establish a common user interface, RSView32 can also realize data storage and alarm functions. The system control program is compiled using the VBA development

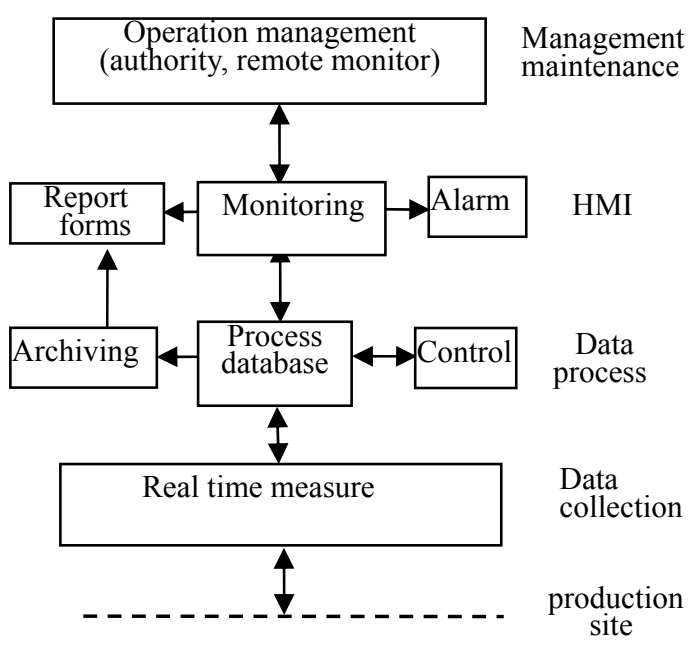

Figure. 10 Hierarchy block diagram of system software environment

\subsection{The running results of system}

Having been debugged on line and operated in experiments, this control system is applied in practical production. Productive statistics data show that fuzzy control and FNN-PID control strategy are reasonable and the temperature control effect is superior to that of PID. The energy consumption has reduced by $3.8 \%$, the firebox temperature is controlled within $\pm 10{ }^{\circ} \mathrm{C}$ and pellet qualification rate has increased by $6.4 \%$.

The application of this system not only improved whole system control capability, reduced the range of temperature change, enhanced product quality and reduced energy consumption, but also eased labor intensity of workers.

\section{Conclusions}

In view of the temperature control of the sintering shaft furnace, a serial temperature control system for sintering pellet furnace is introduced in this paper. In order to keep the total amount of gas and air invariable, the temperature control of firebox is implemented by changing the air/gas ratio. Thus not only the temperature is controlled steadily, but the furnace is also in an oxygenation atmosphere. For this purpose, the serial control system with a main loop and two auxiliary loops is designed, in which the flowrate of gas and air is taken as the control objects. The main loop, which is used to 
adjust the air/gas ratio, is composed of a fuzzy controller whose output is the change of the air/gas ratio. The given values of gas and air control loop can be calculated by the change of the air/gas ratio. The gas and air control loop are controlled by FNN-PID controller.

Since this control system is used, it not only solves the influence of gas calorific change on temperature, but also ensures the oxygenation atmosphere required by the production technique. The application results show that production requirement is met and better control effects are obtained. The aim of energy saving and consumption reduction and quality improvement is achieved.

\section{Acknowledgments}

The authors wish to thank $\mathrm{Mr}$. Wu jianhua and his colleagues for their help. This work was supported in part by the Xingtai Iron and Steel Company.

\section{References}

[1] Wang Qi, Ma Xingya, Sun Jiafu etal, "Problems in Shaft Furnace Pelletizing and Some Countermeasures for Reformation", Sintering and Pelletizing, Vol. 25(3), pp.52-54, 2000.

[2] He Xianrui, "A few of assumes for development of pellet shaft technology". Pelletizing Technology, Vol.(2),pp.2-6,2006

[3] Li Xingwang, "Auto-control System of Magang Pelletizing Plant". Sintering And Pelletizing. Vol. 26(3),pp.14-16, 2001

[4] Wang Feng, Wang Qinghe, "The application of DCS system in pellet shaft furnace", Pelletizing Technology, Vol.2, pp.16-21, 2003.

[5] Fang Huijuan, Wang Yongji, "The Automatic Control System of The Shaft Furnace in Pelletizing Plant of Daye Iron Ore Mine Analysis and Mathematical Morphology", Computing Technology and Automation, Vol.22(3), pp.33-36,2003.

[6] Lou Guohuan, Wang Jianmin, Wang jiawei, "Design and Implementation of Intelligent Serial Temperature Control System for Sintering Shaft Furnace". Proceeding of the 2th International Conference on Intelligent Networks and Intelligent Systems. Tianjin, China, pp.106-109, 2009.

[7] K.Tanaka, T. Kosaki, "Design of a stable fuzzy controller for an articulated vehicle". IEEE Trans. on Systems Man and Cybernetics, Vol.27(3),pp. 552-558, 1997.

[8] Wei Li, "A method for design of a hybrid neural-fuzzy control system based on behavior modeling". IEEE Trans. on Fuzzy Automation Systems, Vol. 5(12), pp.128-137, 1997.

[9] Gui Zhonghua, Liu Zhenkai, "On Improving Overall Performance of Hybrid Learning Algorithm for feedforward Neural Networks". Journal of Northwestern Polytechnical Unpversity, Vol. 17(2), pp.210-215, 1999.

[10]Song Wei, Zhou wei, "The Current Research and the Development Trend of DCS". Industrial Control Computer, Vol.17(11), pp.1-2, 2004. 